\title{
The official unified nomenclature adopted by the HGNC calls for the use of the acronyms, CCN1-6, and discontinuation in the use of CYR61, CTGF, NOV and WISP 1-3 respectively
}

\author{
Bernard Perbal $^{1} \cdot$ Susan Tweedie ${ }^{2} \cdot$ Elspeth Bruford $^{2}$
}

Received: 17 October 2018 / Accepted: 18 October 2018 / Published online: 5 November 2018

(C) The International CCN Society 2018

\begin{abstract}
An examination of the confusion generated around the use of different acronyms for $\mathrm{CCN}$ proteins has been performed by the editors of the HUGO Gene Nomenclature Committee upon the request of the International CCN Society Scientific Committee. After careful consideration of the various arguments, and after polling the community of researchers who have published in the field over the past ten years, the HGNC have decided to adopt and approve the CCN nomenclature for all 6 genes. Effective October 2018, the genes referred to as CYR61, CTGF, NOV and WISP1-3 will be respectively designated by the gene symbols CCN1-6 with corresponding gene names « cellular communication Q2 network factor 1-6». We believe that this decision will be a step towards better communication between researchers working in the field, and will set the stage for fruitful collaborative projects. Accordingly, the Journal of Cell Communication and Signaling, the official journal of the International CCN Society, available both in print and online, constitutes a unique window into the CCN field. This official nomenclature will benefit the international scientific community that is supported by the established and renowned professionalism of the Springer-Nature publishing group.
\end{abstract}

Keywords CYR61 · CTGF · NOV · WISP1 - WISP2 - WISP3 - CCN proteins · CCNgenes · Cellular communication network factor

As the Editor in Chief of JCCS, I will first briefly review, in this editorial, the scientific confusion that developed over the past 25 years in the world of CCN proteins, since their discovery in the 1990s. I will open our columns to the editors of the HGNC who I invited to present their views, and the process that they followed to set up the new official nomenclature that will most certainly constitute a major landmark in the history of the CCN field.

Bernard Perbal

bperbal@gmail.com

Susan Tweedie

hgnc@genenames.org

Elspeth Bruford

hgnc@genenames.org

President International CCN Society, Nice, France

2 HUGO Gene Nomenclature Committee, EMBL-EBI, Hinxton CB10 $1 \mathrm{SD}, \mathrm{UK}$

\section{The context as viewed by the president of the international CCN society}

Back in 1993, P. Bork, a bioinformatician running in silico studies of peptidic functional domains during evolution, reported that a group of newly identified proteins, named CYR61 (for cystein rich 61), CTGF (for connective tissue growth factor), and $N O V$ (for nephroblastoma overexpressed) shared a striking tetramodular organization and a highly conserved primary sequences encoded by five exons that were spliced in a very similar way.

These observations led the author to propose (Bork 1993) that these proteins constitute an « emerging family of growth regulators » that he designated with the $\mathrm{CCN}$ acronym. The choice for the $\mathrm{CCN}$ acronym was based on the first letter in the names of the only three members of the family that had been identified at that time.

Historically, several groups reported the description of proteins being either orthologs or identical to the three founding 
Table 1 Summary of the new official CCN nomenclature

\begin{tabular}{|c|c|c|c|c|}
\hline $\begin{array}{l}\text { New gene } \\
\text { symbol }\end{array}$ & New gene name & $\begin{array}{l}\text { Previous } \\
\text { gene symbol }\end{array}$ & Previous gene name & $\begin{array}{l}\text { Alias gene } \\
\text { symbols }\end{array}$ \\
\hline CCN1 & Cellular communication network factor 1 & CYR61, IGFBP10 & Cysteine rich angiogenic inducer 61 & GIG1 \\
\hline $\mathrm{CCN} 2$ & Cellular communication network factor 2 & CTGF & Connective tissue growth factor & IGFBP8 \\
\hline CCN3 & Cellular communication network factor 3 & NOV & Nephroblastoma overexpressed & IGFBP9 \\
\hline $\mathrm{CCN} 4$ & Cellular communication network factor 4 & $\begin{array}{l}\text { WISP1 } \\
\text { WISP1-OT1 } \\
\text { WISP1 UT1 }\end{array}$ & WNT1 inducible signaling pathway protein 1 & WISP-1 \\
\hline CCN5 & Cellular communication network factor 5 & WISP2 & WNT1 inducible signaling pathway protein 2 & $\begin{array}{l}\text { WISP-2 } \\
\text { CT58 } \\
\text { CTGF-L }\end{array}$ \\
\hline CCN6 & Cellular communication network factor 6 & WISP3 & WNT1 inducible signaling pathway protein 3 & WISP-3 \\
\hline
\end{tabular}

members of the CCN family (for detailed historical reviews see Perbal 2001, 2013).

Another addition to the family arose in 1998 with the description of three new human members of the $\mathrm{CCN}$ family (Pennica et al. 1998) designated WISP (for Wnt induced secreted proteins) (Xu et al. 2000).

The variety of names given to the same proteins identified in different systems led us to publish in 2003 a call for a unified nomenclature after it had been recognised during the second international workshop on the $\mathrm{CCN}$ family of genes held in 2002 (Saint-Malo France) that it « will serve to eliminate confusion in the literature. A consensus was reached to propose a unifying nomenclature for the CCN family, numbering them CCN1 through CCN6 in the order in which they were described in the literature. Thus, CYR61 will be designated CCN1, CTGF as CCN2, NOV as CCN3, and WISP-1-3 as CCN4-6 » (Brigstock et al. 2003, Perbal 2004).

Also, accumulating scientific evidence called for a reassessment of the original acronyms.

For example the overexpression of NOV originally reported in a group of chicken nephroblastomas, did not appear to be a general feature of these tumors, neither in chicken nor in human (Perbal 1994). Similarly there is evidence indicating that CTGF is not a growth factor per se but is rather acting as a co-factor in the regulation of cell growth stimulation of target cells (see Perbal and Perbal 2016).

On an onomastic ground the situation that developed was not in favor of the maximal valorization of these discoveries. Very often, the communications reporting biological properties of any particular protein did not fully exploit or mention the fact that the proteins were part of a family. In the eyes of researchers unaware of these scientific issues, CCN proteins could appear as being unrelated to each other or belonging to separate functional worlds.

On the contrary, the current picture is that the $\mathrm{CCN}$ proteins physically interact with each other and their biological properties are interdependent.
For example, it was well established that the expression of CCN2 (CTGF) and CCN3 (NOV) are cross-regulated with their activities on cell proliferation being opposite and most likely involved in a " yin and yang type » of regulation (Van Roeyen et al. 2008, Kawaki et al. 2008, Riser et al. 2009, Rittié et al. 2011, Kawaki et al. 2011)

These critical observations which cannot be ignored argue against considering $\mathrm{CCN}$ proteins on their own, a misconception that obliterates several aspects of their biology. Instead, all scientific observations concur to call for a cooperatively regulated mode of action (Perbal 2001).

In an attempt to propose a model that could serve as a conceptual basis to collectively address these problems, I have proposed (Perbal 2013, 2018) a dynamic model in which the variety of regulatory functions attributed to the $\mathrm{CCN}$ proteins results from a strict spatiotemporal regulation of a complex series of combinatorial events strictly dependent on the local and timely bioavailability of the proteins and their ligands. These events involve physical interactions of the various $\mathrm{CCN}$ proteins between themselves, and with their specific ligands, in subcellular compartments during normal cellular life.

As we have previously pointed out in a thorough review of the field, evolution over the past 25 years since its inception (Perbal and Perbal 2016), citations in manuscripts in which the CCN acronyms were used increased at a very good pace, in spite of a system which was not helpful. Unfortunately, the recommendation for using a unified nomenclature was not fully observed for various reasons including the fact that companies selling $\mathrm{CCN}$ reagents used the original acronyms officially recognized by the HGNC, and for more personal reasons that we cannot develop here because they go far beyond the aims of public scientific research.

After carefully studying many of the manuscripts published in the field over the past 25 years, we felt that the main problem did not really stem from the few senior groups who remained reluctant to a switch of nomenclature, but from most of the newcomers who joined this expanding field and who were 
not aware of the misconceptions raised by the use of some old acronyms. These issues were regularly debated during the International workshops on the $\mathrm{CCN}$ family of genes, and those who did not attend our meeting referred in good faith to previous publications or quoted the official original acronyms.

In order to clarify the situation and avoid the reinforcement of conflictual positions among researchers working in the same field, the founding members of the Scientific Committee of the ICCNS addressed the major problems resulting from a lax, counter-productive, system of citations not serving the scientific community, and presented to the HGNC the major pitfalls caused by a conservative scientific view.

\section{The context as viewed by the editors of HGNC and steps leading to an official unification}

The HGNC were originally contacted by Professor Lester Lau on behalf of the ICCNS, following their inaugural Saint-Malo meeting in 2000 with a proposal to adopt a unified nomenclature for this family using the $\mathrm{CCN}$ root.

From our point of view there were two major problems the primary one being that the CCN root was already approved for cyclin gene symbols. The second issue was that "CCN" is derived from the very symbols we were being requested to replace (CYR61/CTGF/NOV), so the gene name would confusingly reference obsolete symbols. Our suggestion at that time was to discuss possible alternative unique root symbols for the family but this offer was not taken up, and subsequent discussions following the 2001 St Malo society meeting again stalled. As a result of this impasse, articles have since been published using a mix of the original gene symbols, the $\mathrm{CCN}$ symbols, other aliases and, frequently, a combination of symbols - clearly not an ideal situation.

In 2015 Professor Brahim Chaqour wrote advocating the $\mathrm{CCN}$ system but we felt that, on top of the original two issues, there were already too many papers using the approved symbols, especially $C T G F$. Generally HGNC avoid changes to symbols whenever possible - unless updating a temporary symbol (e.g. C\#orf\#s) or correcting misleading nomenclature. We are particularly reluctant to change highly cited symbols. However, we did create a CCN gene family page (https://www.genenames.org/ cgi-bin/genefamilies/set/1046) at this time in an effort to make it clear that this group of genes with disparate nomenclature are closely related. Finally, we were contacted in November 2017 by Professors Perbal, Lau, Leask and Brigstock with another request on behalf of the ICCNS to change to the CCN symbols. So why, 18 years after the initial contact, have HGNC now agreed to update to this nomenclature?

In 2016, the HGNC instigated our sister project, the Vertebrate Gene Nomenclature Committee (VGNC), for naming genes in vertebrate species that do not have their own nomenclature committee. These genes are named based on their human ortholog, but we are also trying to follow community recommendation not to humanize genes in other species by avoiding transferring human-specific information, such as disease phenotypes. Consequently, we have been reviewing human gene names before transferral to their orthologs, and this process had flagged NOV, "nephroblastoma overexpressed". As well as being phenotype-based, the NOV acronym is also far from ideal for literature searching as it is widely used for other things, especially "November". The ICCNS request arrived as we were considering alternatives for $N O V$. Looking at 300+ papers retrieved about this gene, we noted $C C N 3$ was used in just over half, and hence the pragmatic solution seemed to be to adopt the already well-used alias, $C C N 3$. However, this conflicted with our aim of using the same root symbol for gene family members.

In addition, the ICCNS argued that "connective tissue growth factor" was a misleading name because the gene does not encode a growth factor, and this misnomer had led to researchers misinterpreting their results. As previously stated, we do make symbol changes if the nomenclature is subsequently shown to be misleading. And we also agreed with the ICCNS that "CYR61" is not informative nomenclature the number 61 being essentially meaningless.

This led us to review the usage of symbols for the whole $\mathrm{CCN}$ family and to investigate the extent to which there is confusion with the cyclins. The cyclin symbols follow the pattern CCN-letter-(number) (e.g. CCNE1), though CCNA2 was originally approved as $C C N 1$, and normally we would not contemplate reusing a symbol that was ever approved for another gene. A literature search (title and abstract) using ' $\mathrm{CCN} 1$ ' found almost 400 papers - the vast majority of which refer to CYR61/ $C C N 1$, with only ten referring to the Candida albicans cyclin gene $C C N 1$. We did not retrieve cyclin papers in searches with CCN2-6. Nevertheless, regardless of the lack of confusion in the literature, we still retain reservations about sharing a root symbol with the cyclins and still feel it would have been preferable to have agreed a distinct root symbol back in 2000.

In terms of symbol usage, the approved symbols were also more published than the $\mathrm{CCN}$ symbols for all the genes other than $N O V / C C N 3$. However, we noted a trend towards the $\mathrm{CCN}$ nomenclature over time by the majority of authors who published most on these genes. Therefore, we informed the ICCNS that we would conduct a wide consultation with the research community on the proposal to update to the $\mathrm{CCN}$ nomenclature, as long as we could adopt a gene name that did not reference the old symbols - which resulted in "cellular communication network factor". With almost 5000 publications on all six genes, we chose to be pragmatic and email the 164 corresponding authors of 3 or more publications on any CCN gene in the last 10 years. Authors were asked if they supported the proposal to adopt the unified CCN nomenclature, and also if it should include WISP1-3, as we did not feel the case to rename these genes was as compelling as for CYR61, CTGF and NOV. 
From the responses received only two authors expressed concerns and only two were wholly against the proposal. The major concern was that the link to the extensive literature using the original gene symbols could be lost. We completely understand this concern, and always ensure that all previous names and symbols are retained in the gene record - both in our database and others such as NCBI Gene. Medline/PubMed also link previous symbols to approved symbols via $\mathrm{MeSH}$, so the past literature should still be easily found. Other comments included a request to rename the mouse genes in line with human, and we can confirm that the Mouse Gene Nomenclature Committee will do this, and other vertebrates will also follow in due course. It was also confirmed that it is important to include the WISP genes as $C C N 4-6$, as otherwise their membership of the family may be overlooked and important insights into their functions neglected.

There are always some regrets at the loss of a long-standing symbol that reflects the history of a gene's discovery, there was speculation that the new nomenclature won't be adopted, and reservations about the meaningfulness of the new gene name. However, these concerns were outnumbered by the enthusiastic support for the proposal, and hence the new approved CCN family can now be found in our database and will disseminate to other resources in due course. We hope that the new CCN family nomenclature (Table 1) is universally welcomed and trust that you will use it in all future publications. We also strongly encourage any readers to contact the HGNC (hgnc@genenames.org) about any new gene nomenclature proposals prior to publication - we are under increasing pressure not to change any symbols due to their increasing use in genomic medicine, and so we can't make a habit of being this accommodating!

\section{From historical milestones to the hopes brought by the official recognition of the CCN acronym}

The official recognition of the $\mathrm{CCN}$ nomenclature provides the ground for a unique scientific and human reunion of the researchers working in the field.

In the year 2000, after I had consulted with my friend and colleague Dr. Herman Yeger, I had felt that it was time to bring together the researchers working on the newly discovered $\mathrm{CCN}$ genes and proteins. Thanks to the dedication and help of Annick, we could organize the first international workshop on the CCN family of genes in Saint-Malo (France).

Bringing together the leaders in the field was not only a great and scientific adventure but a superb opportunity to meet and put a face on those people who discovered the CCN genes, and who were already involved in very productive research aimed at deciphering the biological properties of this unique family of proteins.
It was also the time to propose a framework that would allow us to keep meeting and exchanging new ideas and set up collaborative projects in a friendly open way.

Very soon the ICCNS was born and I created « CCS: Cell Communication and Signaling ", the official organ of the ICCNS, which was at that time the first open access journal focusing on intercellular signaling.

The audience of the journal was ramping up when Biomed Central reinforced the need to pay for submission, a view that was not shared by the members of our editorial board. I will not come back to the reasons why we decided to leave BMC and became hosted, as a non profit society by Springer, but I wish to stress that this move created a hard time for all of us, especially when BMC decided, after we had developed with Springer the Journal of Cell Communication and Signaling (JCCS available at http://springer.com/12079) to keep on publishing, with the same name the journal that I had created, thereby generating a confusion in the mind of potential authors. ${ }^{1}$

Since then, JCCS has been recognized as a reference publication in the field of cellular signaling with an impact factor in the range of 3.0 to 2.5 since 2016 .

As I mentioned above, JCCS was created as the official journal of the $\mathrm{CCN}$ community.

It offers a rapid turn-around review process, in print and online, published by Springer-Nature with no submission fees, including colour photographs (see http://springer.com/12079).

\section{JCCS: Ten years later}

JCCS is now recognized as a unique niche for studies dealing with molecular and translational research, and for publications reporting progress in the understanding of extracellular matrix signaling.

It is the journal of choice for the publication of $\mathrm{CCN}$ manuscripts.

On the occasion of the JCCS 10th birthday, the vast majority of our Editors accepted to participate in the publication of a splendid 40-article special issue, that shed light on their present scientific activities (https://link.springer.com/article/10. 1007/s12079-018-0472-4).

The variety of topics covered by these communications reflects the central position that JCCS holds in the field of intercellular communication and cross-talk of cells with their microenvironment.

The manuscripts contained in this special issue covered several fundamental biological pathways in which cell communication and signaling play key roles, both in normal and pathological conditions, including cancer and aging (15 contributions), vasculature (3 contributions), development (4

\footnotetext{
${ }^{1}$ For more details about these aspects, see: B. Perbal (2015) What kind of a life for a scientific journal? J Cell Commun Signal. Sep;9(3):201-206.
} 
contributions), bone and cartilage (4 contributions), fibrosis, injury and inflammation (14 contributions).

Let me take this opportunity to express my deepest appreciation to all those who particpated in the production of this issue.

We believe that JCCS could be a powerful vector in the communication of scientific progress and new ideas in the CCN field.

As we previously mentioned (Perbal and Perbal 2016) « « The proposal for a unified nomenclature combined with efforts that we have deployed to organize meetings along with an official journal for reporting $C C N$ research were meant to consolidate the relationships between researchers who would otherwise ignore each other. Being part of a community is an essential aspect of modern science. We are convinced that the whole community will benefit from everybody " playing the same game ", and we would like to take this opportunity to renew our suggestion and invite all researchers working in the great field of CCN research to join us».

This is, in our view, the only way to unite our forces and better understand the wide range of complex biological functions played by this fascinating family of proteins.

We are presently in the process of "rejuvenating" the editorial board of JCCS after 10 years of increasing quality in publication.

It is good timing to take advantage of the ground offered by officialization of the CCN acronym and make this journal a stronger medium for publishing in the CCN field.

Along this line, myself and Andrew Leask would be happy as the Editor in Chief, and Managing Editor of JCCS, to consider applications from those who used to publish with the previous acronyms, to join our editorial board and directly participate in the development of JCCS to make it « THE » reference for $\mathrm{CCN}$ publications.

As a second step in our effort to foster positive interactions, let me bring to the attention of colleagues who might ignore the activities of our non profit scientific society, that we organize very successful biennial workshops ${ }^{2}$ that are the only scientific meetings focusing on various aspects of $\mathrm{CCN}$ biological activities in normal and pathological conditions.

In our opinion, JCCS and the ICCNS can be the most exquisite tools for the $\mathrm{CCN}$ community to exchange leading ideas and reliable reagents, using the print medium and via the $\mathrm{CCN}$ society journal, or live by participating in the $\mathrm{CCN}$ workshops.

We are eager to hear from you and meet you all soon.

Acknowledgements I am grateful to H. Yeger and A. Perbal for critical reading of the manuscript.

\section{References}

Bork P (1993) The modular architecture of a new family of growth regulators related to connective tissue growth factor. FEBS Lett 327: $125-130$

Brigstock DR, Goldschmeding R, Katsube KI, Lam SCT, Lau LF, Lyons K, Naus C, Perbal B, Riser B, Takigawa M, Yeger H (2003) Proposal for a unified CCN nomenclature. J Clin Pathol Mol Pathol 56:127-128

Kawaki H, Kubota S, Suzuki A, Lazar N, Yamada T, Matsumura T, Ohgawara T, Maeda T, Perbal B, Lyons KM, Takigawa M (2008) Cooperative regulation of chondrocyte differentiation by $\mathrm{CCN} 2$ and CCN3 shown by a comprehensive analysis of the CCN family proteins in cartilage. J Bone Miner Res 23(11):1751-1764. https://doi. org/10.1359/jbmr.080615

Kawaki H, Kubota S, Suzuki A, Suzuki M, Kohsaka K, Hoshi K, Fujii T, Lazar N, Ohgawara T, Maeda T, Perbal B, Takano-Yamamoto T, Takigawa M (2011) Differential roles of CCN family proteins during osteoblast differentiation: Involvement of Smad and MAPK signaling pathways. Bone 49(5):975-989. https://doi.org/10.1016/j.bone. 2011.06.033

Pennica D, Swanson TA, Welsh JW, Roy M, Lawrence D, Lee J, Brush J, Taneyhill L, Deuel B, Lew M, Watanabe C, Cohen R, Melhem M, Finley G, Quirke P, Goddard A, Hillan K, Gurney A, Botstein D, Levine A (1998) WISP genes are members of the connective tissue growth factor family that are up-regulated in Wnt-1-transformed cells and aberrantly expressed in human colon tumors. Proc Natl Acad Sci U S A 95:14717-14722

Perbal B (1994) Contribution of MAV-1-induced nephroblastoma to the study of genes involved in human Wilms' tumor development. Crit Rev Oncog 5(6):589-613

Perbal B (2001) NOV (nephroblastoma overexpressed) and the CCN family of genes: structural and functional issues. Mol Pathol 54: $57-79$

Perbal B (2004) CCN proteins: multifunctional signalling regulators. Lancet 363(9402):62-64

Perbal B (2013) CCN proteins: A centralized communication network. J Cell Commun Signal 7(3):169-177. https://doi.org/10.1007/ s12079-013-0193-7

Perbal B (2018) The concept of the CCN protein family revisited: a centralized coordination network. J Cell Commun Signal 12(1):312. https://doi.org/10.1007/s12079-018-0455-5

Perbal A, Perbal B (2016) The CCN family of proteins: a 25th anniversary picture. J Cell Commun Signal 10(3):177-190

Riser BL, Najmabadi F, Perbal B, Peterson DR, Rambow JA, Riser ML, Sukowski E, Yeger H, Riser SC (2009) CCN3 (NOV) is a negative regulator of CCN2 (CTGF) and a novel endogenous inhibitor of the fibrotic pathway in an in vitro model of renal disease. Am J Pathol 174(5): 1725-1734

Rittié L, Perbal B, Castellot JJ Jr, Orringer JS, Voorhees JJ, Fisher GJ (2011) Spatial-temporal modulation of CCN proteins during wound healing in human skin in vivo. J Cell Commun Signal 5(1):69-80

van Roeyen CR, Eitner F, Scholl T, Boor P, Kunter U, Planque N, Gröne HJ, Bleau AM, Perbal B, Ostendorf T, Floege J (2008) CCN3 is a novel endogenous PDGF-regulated inhibitor of glomerular cell proliferation. Kidney Int 73(1):86-94

Xu L, Corcoran RB, Welsh JW, Pennica D, Levine AJ (2000) WISP-1 is a Wnt-1- and beta-catenin-responsive oncogene. Genes Dev 14(5): 585-595

\footnotetext{
${ }^{2}$ The preliminary program of the next workshop to be held at Niagara Falls is
available on the ICCNS web site (http://ccnsociety.com). It will be updated on a

2 The preliminary program of the next workshop to be held at Niagara Falls is
available on the ICCNS web site (http://ccnsociety.com). It will be updated on a regular basis. Reports of the workshops are published in JCCS. Last report is accessible online at https://link.springer.com/article/10.1007/s12079-018-0472-4
} 